\title{
Dislocations and Grain Boundaries in Ceramics and Metals
}

\author{
C. Barry Carter $^{1}$
}

1. Departments of MSE and CBE, University of Connecticut, Storrs, CT USA

This paper is offered as a tribute to the late Gareth Thomas and the celebration of his career using transmission electron microscopy. His early work on dislocations and twin boundaries in metals suggested indirect methods for determining the stacking-fault energies (SFEs) of Al [1] and Ni [2] and subsequently examined questions on how the measured values of SFEs of copper alloys change when the material is heat-treated or short-range order is present [3, 4]. Although measurements [5, 6] using the weak-beam technique overtook the use of indirect determinations, the latter were influential and are still relevant. Actually Thomas did propose his own version of the weak-beam technique - using the brightfield mode — which certainly has merit and is often applied, even if is not widely recognized.

In ceramics, perhaps Thomas's most lasting important work was the demonstration that grain boundaries in these materials can be completely coated with a very thin layer of amorphous material[7]. This observation harkens back to the earliest days of grain boundary analysis when all such interfaces were thought to be disordered. The implications of these observations are still the subject of debate and extensive research [8,9]. The characterization of phase transformations in the TEM (e.g., [10]) and the identification of long-period polytypes [11] has also raised considerable interest in the ceramics field.

From a general TEM point of view, it was Thomas and colleagues who really demonstrated the importance of transmission Kikuchi diffraction maps [12-15], a phenomenon whose importance and applicability is becoming even more widely recognized today [16].

In the present paper, I will examine the state of our understanding of some topics addressed in Thomas's early work, namely dislocation mechanisms in tantalum [17], the use of in-situ observations to understand reaction processes [18], and processes in nanostructured functional materials [19]; when possible, I will select systems that could not be addressed just a few years ago as illustrated by Figures 1 and 2. In doing so, I will address questions such as - are dislocations still important? And if so, is it enough to just simulate them? Modeling papers may be more frequently referenced than those giving experimental data, but is this a valid approach without experimental data? If time permits, we will ask: is there a future for TEMs operating at higher voltages? [20]

References:

[1] Kannan VC, Thomas G (1966) J ApplPhys 37: 2363-\&

[2] Nolder RL, Thomas G (1964) Acta Metall 12: 227-240

[3] Bell W, Okamoto P, Thomas G (1965) Acta Metall 13: 559-561

[4] Thomas G (1963) Acta Metall 11: 1369-1371

[5] Carter CB, Ray ILF (1977) Philos Mag 35: 189-200

[6] Carter CB, Holmes SM (1977) Philos Mag 35: 1161-1172

[7] Clarke DR, Thomas G (1977) J Am Ceram Soc 60: 491-495

[8] Protasova SG et al (2014) J Mater Sci 49: 4490-4498

[9] Baram M, Kaplan WD (2006) J Mater Sci 41: 7775-7784

[10] Goto Y, Thomas G (1995) J Mater Sci 30: 2194-2200

[11] Vantendeloo G, Faber KT, Thomas G (1983) J Mater Sci 18: 525-532

[12] Vonheimendahl M, Thomas G, Bell W (1964) J Appl Phys 35: 3614-\& 
[13] Levine E, Bell WL, Thomas G (1966) J Appl Phys 37: 2141-\&

[14] Thomas G, Bell WL, Otte HM (1965) Phys Stat Sol 12: 353-366

[15] Johari O, Thomas G (1969) The stereographic projection and its applications. Interscience Pubs,

New York

[16] Ozdol VB et al (2015) Appl Phys Lett 106: 253107-253101-253105

[17] Lau SS et al(1967) Acta Metall 15: 237-\&

[18] Swann PR, Thomas G, Tighe NJ (1973) J Microsc 97: 249-257

[19] Thomas G (2004) Prog Mater Sci 49: 607-626

[20] The author acknowledges Matt Janish and Bill Mook for many discussions, Dr. Paul G. Kotula for the STEM imaging of $\mathrm{WS}_{2}$ and $\mathrm{MoS}_{2}$ and Drs Stanley Chou and Jeff Brinker for the specimens of these exfoliated materials.
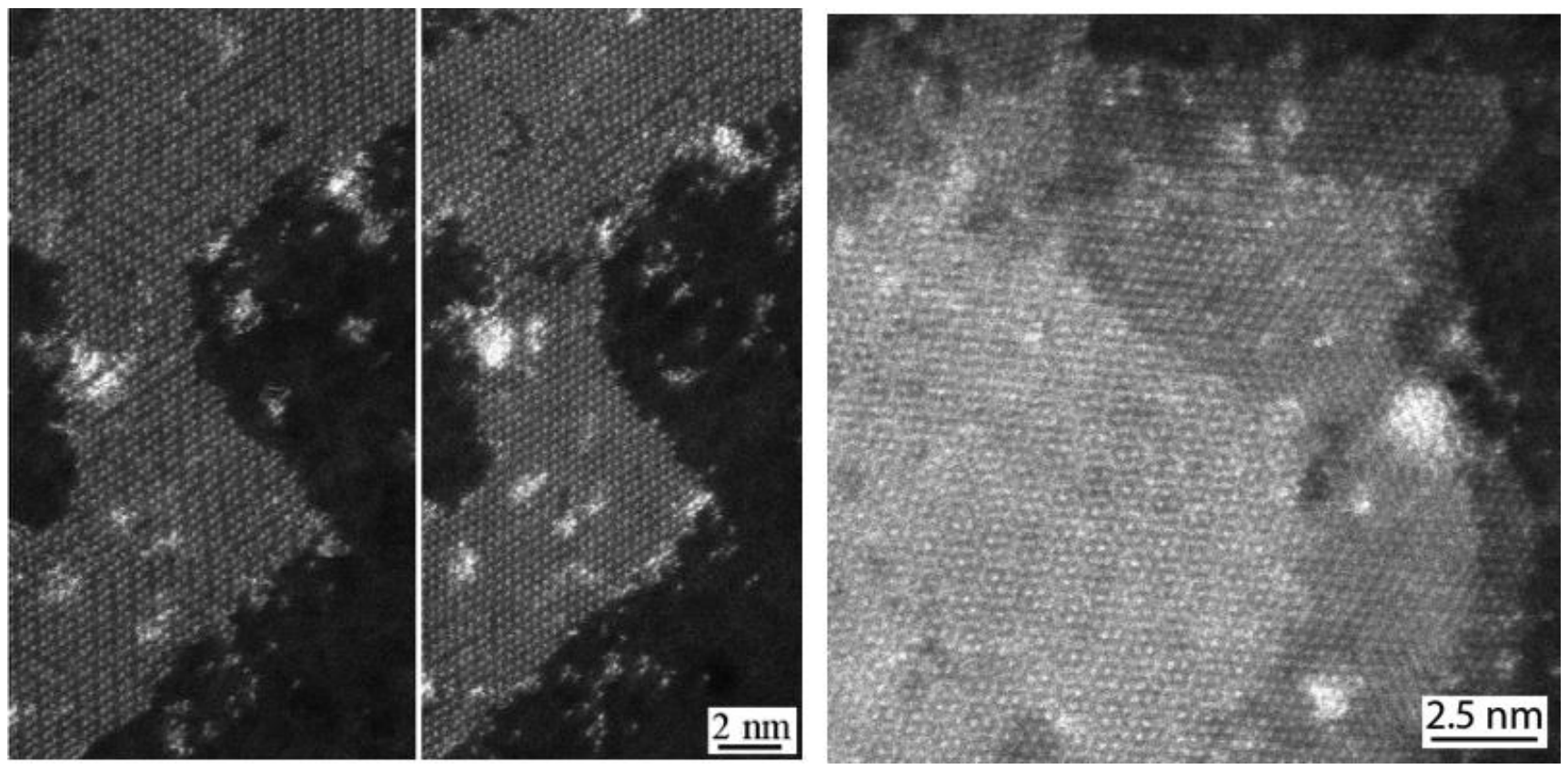

Figure 1. (left 2): A region of a monolayer of $\mathrm{WS}_{2}$ after repeated scan in a 200kV STEM;

Figure 2. (right): A twist boundary in a tri-layer of $\mathrm{MoS}_{2}$. 